\title{
Evaluation of $\alpha$-Amylase Inhibitory, Antioxidant and Cytotoxic Activities of Mimusops elengi Seeds
}

\author{
Al Mamun ${ }^{1}$, Sabina Easmin ${ }^{1}$, Ashru Ahmed ${ }^{1}$, Md. Rezaul Haque Ansary ${ }^{1}$, \\ Wasim Bary ${ }^{2}$, Md Shahed Zaman ${ }^{1}$ and Hamidul Haq ${ }^{1}$ \\ ${ }^{1}$ Department of Chemistry, University of Rajshahi, Rajshahi-6205, Bangladesh \\ ${ }^{2}$ Department of Biochemistry and Molecular Biology, University of Rajshahi, Rajshahi-6205, Bangladesh
}

(Received: June 4, 2021; Accepted: December 24, 2021; Published (web): January 29, 2022)

\begin{abstract}
Mimusops elengi Linn., locally known as "Bakul, is a commonly used medicinal plant in Bangladesh to treat several maladities. The purpose of this study was to investigate the antioxidant, $\alpha$-amylase inhibitory and cytotoxic activity of four different solvent fractions such as petroleum ether, chloroform, ethyl acetate, and water of $M$. elengi seed. In this study, the high ferric reducing $(1.74 \pm 0.005)$ and DPPH free radical scavenging activity $\left(\mathrm{IC}_{50} 39.49 \pm 0.05 \mu \mathrm{g} / \mathrm{ml}\right)$ was observed in the ethyl acetate fraction. The highest amount of flavonoid content $(1059.80 \pm 2.15 \mathrm{mg}$ of CE/g) and total antioxidant capacity $(0.17 \pm 0.005)$ was present in chloroform fraction. On the other hand, the ethyl acetate fraction exhibited the highest total phenolic content $(182.90 \pm 0.38 \mathrm{mg}$ of GAE/g). Crude methanolic extract showed highest inhibition of $\alpha$-amylase with $\mathrm{IC}_{50}$ value of $4.09 \pm 0.08 \mathrm{mg} / \mathrm{ml}$. The brine shrimp lethality bioassay of ethyl acetate fraction exhibited maximum toxicity with low $\mathrm{LD}_{50}$ value $127.10 \mu \mathrm{g} / \mathrm{ml}$. Thus, extracts of $M$. elengi seed could be a source of antioxidant, cytotoxic and $\alpha$-amylase inhibitory activity containing compounds.
\end{abstract}

Key words: Mimusops elengi, phytochemical screening, antioxidant, $\alpha$-amylase inhibitory, cytotoxicity.

\section{Introduction}

In this era, research on natural products has received a great attention. According to world health organization (WHO), about $70 \%$ of the world population is still depending on natural medicines to fulfill their health requirements (Uddin et al., 2012). Now a day, consumption of the natural chemical constitutes enriched foods become interested because of growing awareness of the health benefits. Biologically active chemical constitutes of natural products can be used as a pharmaceutical, nutraceuticals, essential functional foods, and food additives for human health advantage because of their different kinds of structures and functionalities.

According to the International Diabetes Federation (2012), the pervasiveness of diabetes is rising at a worrying order throughout the world and it is assessed that more than 552 million people will be affected by type 2 diabetes within 2030. Therefore, blood glucose levels should be controlled for delay or prevent type 2 diabetes. The enzyme $\alpha$-amylase catalyzes the hydrolysis of starch to oligosaccharides and disaccharides in the digestive system. Inhibition of this enzyme suppress blood glucose rising by retard the initial breakdown of starch before liberating complex or simple sugars (Ademiluyi and Oboh, 2013).

At present, biologically active constituent such as phenolics have been reported as a strong antioxidant having inhibition against the action of $\alpha$ amylase and $\alpha$-glucosidase enzymes in vitro (Kwon et al., 2008; Cheplick et al., 2010; Oboh et al., 2012). These bioactive compounds may bring down the conversion of starch into glucose and hence bring 
down postprandial plasma glucose levels along with other diabetic related complications developing from oxidative stress (Pranprawit et al., 2015). On the other hand, synthetic inhibitors have been found to cause numerous unwanted side effects which led to the search for alternative $\alpha$-amylase inhibitor from natural products, particularly, a food or medicinal plant origin in recent years to be tested as potentially safer, low cost anti-hyperglycemic agents (Kwon et al., 2008; Oboh et al., 2012).

In Bangladesh, all part of $M$. elengi plant is consumed traditionally by large number of people for many illnesses. It was observed that different parts of this plant exhibited various biological activities such as leaves possess antioxidant, anti-inflammatory (Ganesh et al., 2013), antibacterial (Padhi and Mahapatra, 2013), and cytotoxic activities (Karmakar et al., 2011). Bark shows wound healing (Gupta and Jain, 2011), diuretic activities (Koti and Ashok, 2010). In addition, flowers show hypoglycemic effect (Zahid et al., 2012). Only antibacterial activity of $M$. elengi seed was examined. But seed extracts did not show any effect against gram positive and gram negative strains (Shahwar, D. and Raza, M.A., 2009). No researches have been studied on the $\alpha$-amylase inhibition and antioxidant activity of $M$. Elengi seed. Thus, the present study aims to investigate the highest inhibitory potential of $\alpha$-amylase and antioxidant activity of Mimusops elengi Linn. seed by using both polar and non-polar solvent.

\section{Materials and Methods}

Chemicals and reagents: In this study, all the chemicals used were of analytical grade. Petroleum ether, chloroform, ethyl acetate, methanol, sodium carbonate, ascorbic acid, potassium buffer, trichloroacetic acid and sodium hydroxide were purchased from Merck, Germany. Aluminium chloride, sulphuric acid, dimethyl sulfoxide and 3,5dinitrosalicylic acid were obtained from Merck, Mumbai, India. Folin-ciocalteau, gallic acid, DPPH and sodium phosphate were bought from Sigma Chemical Company, USA. Catechin (Wako Pure Chemicals Ltd., Japan), sodium nitrite (Thomas
Baker, Mumbai), ammonium molybdate (The British Drug house Ltd, England), potassium ferricyanide (Matheson Coleman and Bell, America), ferric chloride (Loba Chemic Pvt Ltd, Mumbai) and $\alpha$ amylase enzyme (Sigma-Aldrich, Germany) were procured from the mentioned sources.

Collection and extraction of plant material: The fruits of M. elengi were collected from the campus of University of Rajshahi, Rajshahi, Bangladesh during April to May. The plant species were authenticated (voucher specimen no. 125) at the Department of Botany, University of Rajshahi. Then the seeds were taken out from the fruits at that time. The collected seeds were washed with clean water, dried in air and ground to a coarse powder with an electric grinder (PHILIPS, HL7750/00). The pulverized seeds were stored in an airtight container until used. About 1618 $\mathrm{gm}$ of powdered seed were macerated with methanol in a 2.5 litre glass container at room temperature and kept for 48 hours with shaking occasionally. The extract was filtered by using Whatman no. 1 filter paper, and the solvent was evaporated by using the Buchi Rota-vapor (R-200; DS, MODEL: WB-1000E) under reduced pressure at $45^{\circ} \mathrm{C}$. Finally, the extract was dried by using nitrogen gas. The crude methanolic extract was dissolved in $10 \%$ aqueous methanol and then fractionated with petroleum ether, chloroform, and ethyl acetate to provide pet ether, chloroform, ethyl acetate and water soluble fractions. Then all fractions were subjected to bioactivity test.

Phytochemical screening: Qualitative phytochemical screening of some major secondary metabolites such as saponins, tannins, glycosides, steroids, alkaloids, phenol and flavonoids in $M$. elengi seed was carried as per the published methods (Khandelwal et al., 2008; Harborne et al., 1998; Wadood et al., 2013) with some modifications. The presence of major secondary metabolites was generally confirmed by visual inspection of color and precipitate formation after addition of specific test reagents.

Estimation of total phenolic and flavonoid content (TPC and TFC): Total phenolic content was determined by using the Folin-Ciocalteu reagent 
(Slinkard and Singleton, 1977; Mcdonald et al., 2001). About $0.30 \mathrm{ml}$ of each sample $(1000 \mu \mathrm{g} / \mathrm{ml}$ by methanol) was transferred in triplicate to the vial.

A gallic acid standard curve with varying concentrations $(5,10,20,40,80,100 \mu \mathrm{g} / \mathrm{ml})$ was constructed by plotting gallic acid concentration on the abscissa and absorbance on ordinates for quantification of total phenolic value.

Total flavonoid content assay was performed using aluminum chloride colorimetric technique by following the slightly modified method described by Olajire and Azeez (2011).

Determination of total antioxidant capacity: The total antioxidant capacity of the methanolic extract and its four fractions were assessed spectrophotometrically by the phosphomolybdenum method according to the procedure described by Prieto et al. (1999) with minor modifications and ascorbic acid used as the standard.

Determination of ferric reducing power: The ferric reducing power of $M$. elengi seed extracts was investigated by using the potassium ferricyanideferric chloride according to the procedure described by Oyaizu et al. (1986) with some modifications by using ascorbic acid used as a standard.

Determination of DPPH free radical scavenging activity: The DPPH method was used to evaluate the free radical scavenging activity of the extracts of $M$. elengi seed according to Choi et al. (2000) with few modifications.

The percentage of DPPH radical scavenging activity was calculated by using the following formula.

$\%$ DPPH radical scavenging activity $=\left[\left(\mathrm{A}_{\text {control }^{-}}\right.\right.$ $\left.\mathrm{A}_{\text {sample }} / \mathrm{A}_{\text {control }}\right] \times 100$

The $\%$ of scavenging was plotted against concentration and from the graph the $\mathrm{IC}_{50}$ value was calculated. Ascorbic acid was used as standard for this study.

Determination of in vitro $\alpha$-amylase inhibitory activity: Inhibition of $\alpha$-amylase enzyme was determined according to the procedure described by Jabir et al. (2014) with some modifications.
The $\mathrm{IC}_{50}$ values were determined from the plots of $\%$ of inhibition vs inhibitor concentration. Acarbose was used as a standard.

Determination of cytotoxic activity: Brine shrimp (Artemia salina) lethality bioassay was used for evaluation of cytotoxic activity of $M$. elengi seed extracts according to the method described by Meyer et al. (1982) and Parvin et al. (2009) with some modifications. Brine shrimp eggs were collected from Natore Fishing Agriculture and Research Center, Rajshahi, Bangladesh. Eggs were placed in a $1000 \mathrm{ml}$ beaker containing artificial sea water $(3.8 \%$ of sodium chloride, $\mathrm{pH} 8$ to 9) for $48 \mathrm{hrs}$ with constant oxygen supply at $37^{\circ} \mathrm{C}$. After $24 \mathrm{hrs}$ of hatching period, the nauplii were ready for the experiment. Solution of the seed extracts and standard with concentrations 600, 300, 150, 75 and $37 \mathrm{ppm}$ were prepared by using dimethyl sulfoxide (DMSO). The prepared solutions were taken in six test tubes and twenty brine shrimp nauplii were then placed in each test tube. Volume of liquid was adjusted by brine water and the controls were also arranged in the same fashion in DMSO without the extracts. After 24 hours of incubation, the test tubes were observed at $6^{\text {th }}, 12^{\text {th }}$, $18^{\text {th }}$ and $24^{\text {th }}$ hrs using a magnifying glass and the number of survivors in each tube was counted. Vincristine sulfate and DMSO was used as the positive control and negative control, respectively.

\section{Statistical analysis}

All experiments were performed in triplicate. The TFC, TPC and DPPH assays results have been expressed as means \pm SD using Microsoft Excel. The enzyme analysis was assessed by one-way analysis of variance (ANOVA) and Tukey's comparison test. A $\mathrm{p}<0.05$ value was regarded as significant. Probit analysis was used to determine the $\mathrm{LD}_{50}$ values, $95 \%$ confidence limits and regression equations for each extract and standard from the mortality data. The cytotoxicity of the extracts was compared with the standard gallic acid. Probit software was used to calculate the $\mathrm{LD}_{50}$ value from the mortality data. 


\section{Results and Discussion}

The present study was carried out to evaluate the antioxidant, $\alpha$-amylase inhibitory activity and cytotoxicity of $M$. elengi seed extracts and the results have been summarized in different tables and figures.

The results of phytochemical screenings of the crude methanolic extract and four different fractions of $M$. elengi seed are depicted in Table 1.

The crude extract and all fractions were found to contain glycosides. On the other hand, alkaloids could not be detected in any of the test samples. Saponins, tannins, steroids and flavonoids were also present in the crude extract and some of its partitionates. The result of this study was found to be in agreement with the previously available reports on the same plant (Gami and Parabia, 2010).

Total phenolic and flavonoid contents of the different fractions and crude extract of M. elengi seed are shown in figure 1 and figure 2, respectively.

Table 1. Phytochemical screening of the crude methanol extract of M. elengi seeds and its four fractions.

\begin{tabular}{|c|c|c|c|c|c|c|}
\hline $\begin{array}{l}\text { Phytochemical } \\
\text { constituents }\end{array}$ & Name of test & $\begin{array}{l}\text { Crude } \\
\text { extract }\end{array}$ & $\begin{array}{l}\text { Petroleum } \\
\text { ether } \\
\text { fraction }\end{array}$ & $\begin{array}{c}\text { Chloroform } \\
\text { extract }\end{array}$ & $\begin{array}{c}\text { Ethyl } \\
\text { acetate } \\
\text { fraction }\end{array}$ & $\begin{array}{c}\text { Water } \\
\text { Fraction }\end{array}$ \\
\hline Saponins & Frothing test & +++ & - & + & ++ & ++ \\
\hline Tannins & Lead acetate test & +++ & - & - & + & - \\
\hline Glycosides & Bal Jets test & +++ & ++ & +++ & ++ & ++ \\
\hline \multirow[t]{2}{*}{ Steroids } & Libermann-Burchard's test & +++ & ++ & + & - & - \\
\hline & Salkowski test & +++ & +++ & ++ & - & - \\
\hline Alkaloids & Mayer's test & - & - & - & - & - \\
\hline Phenol & Ferric chloride test & ++ & - & + & ++ & + \\
\hline Flavonoids & Shinoda test & ++ & - & + & ++ & - \\
\hline
\end{tabular}

"+" = small amount, "++" = moderate amount, "+++" = large amount, "-" = not present.

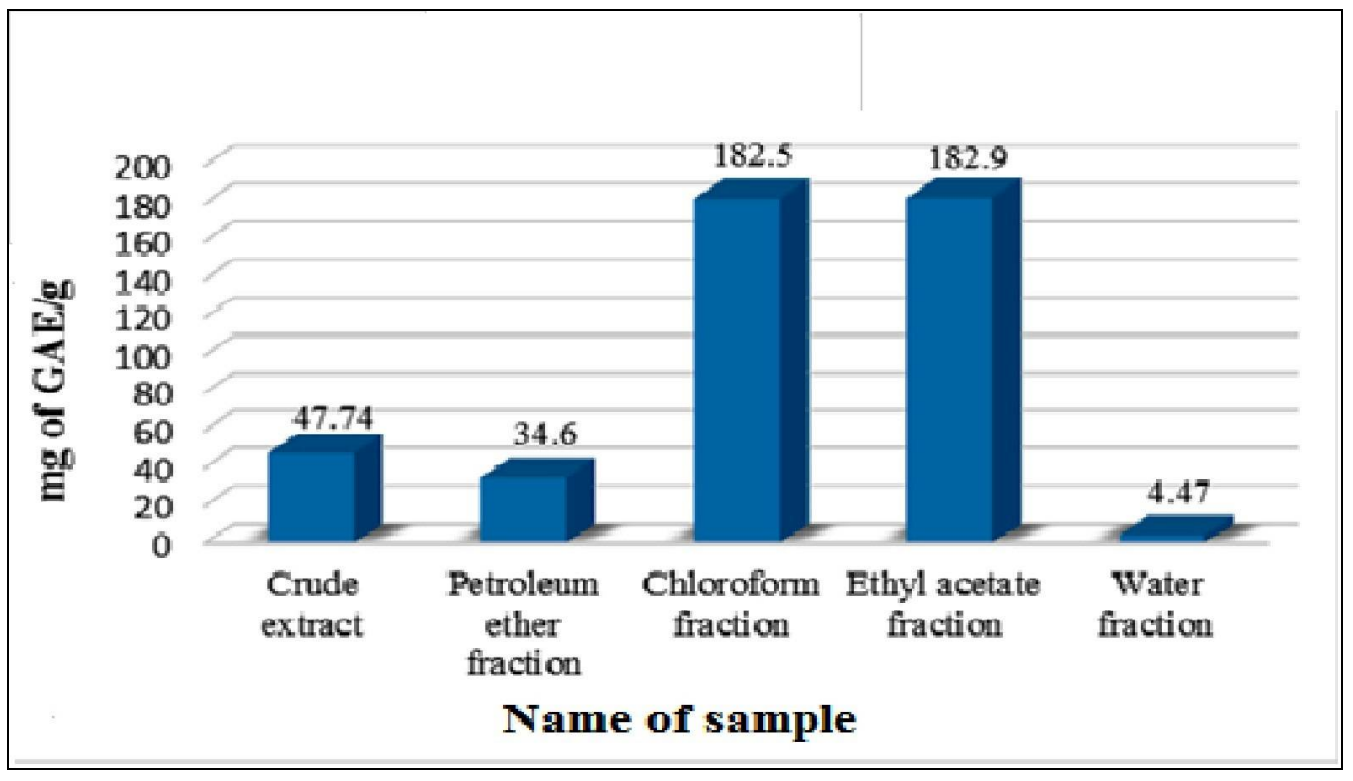

Figure 1. Total phenolic contents of methanolic crude extract of M. elengi seed and its different fractions. 


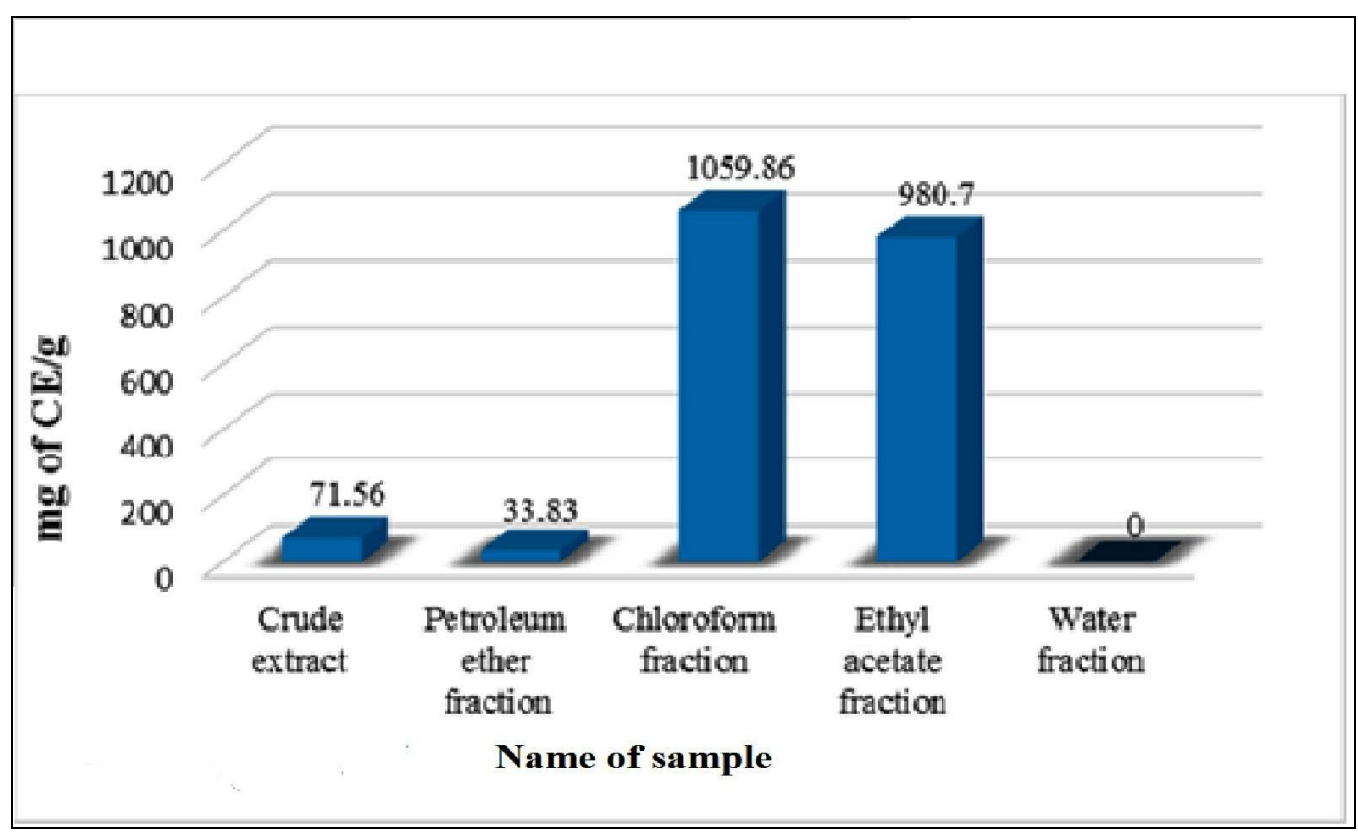

Figure 2. Total flavonoid contents of methanolic crude extract of M. elengi seed and its different fractions.

The result showed that ethyl acetate fraction has high phenolic content with the value of $182.90 \pm 0.38$ $\mathrm{mg}$ of GAE/g of dried extract. The water fraction showed lower phenol content with the value $4.47 \pm$ $0.19 \mathrm{mg}$ of GAE/g of dried extract. This essential changeability pointed out the influence of solvents on the extractability of phenolic compounds. By several studies, it was well-known that phenols are moderately polar compounds, thus they tend to gather in the fraction of medium polarity solvent such as ethyl acetate. The similar results were observed when using this solvent for the extraction of different medicinal plant (Wei et al., 2010; Mariem et al., 2014; Mariod et al., 2009; Mannan et al., 2017). Ethyl acetate is used as solvent for the extraction of low-molecular-weight phenolic compounds and highmolecular-weight polyphenols (Dauer et al., 2003).

In the present study, high flavonoid content was observed in chloroform fraction with the value $1059.80 \pm 2.15 \mathrm{mg}$ of $\mathrm{CE} / \mathrm{g}$ of dried extract and it was absent in the aqueous fraction.
Figure 3 shows the total antioxidant capacities of the four different fractions and crude extract of $M$. elengi seed as well as the standard ascorbic acid.

The chloroform fraction of $M$. elengi seed extract exhibited highest antioxidant capacity $(0.17 \pm 0.005)$ compared with standard $(0.35 \pm 0.005)$. It can be deduced that maximum total flavonoid content in chloroform fraction is responsible for the highest total antioxidant capacity (Prasain et al., 2010). The result is agreeable with that of reported by Mannan et al. (2017) which showed the highest antioxidant capacity of the ethyl acetate fraction obtained from the leaves of $M$. elengi. Thus, the result of total antioxidant capacity of $M$. elengi seeds extract followed the order of chloroform>ethyl acetate>methanol extract (crude) $>$ petroleum ether>water.

The ferric reducing power was analyzed to determine the reducing power of methanol extract and the fractions of $M$. elengi seeds. Ferric reducing power of the four different fractions and crude extract of $M$. elengi seeds in addition to the standard ascorbic acid are depicted in figure 4 . 


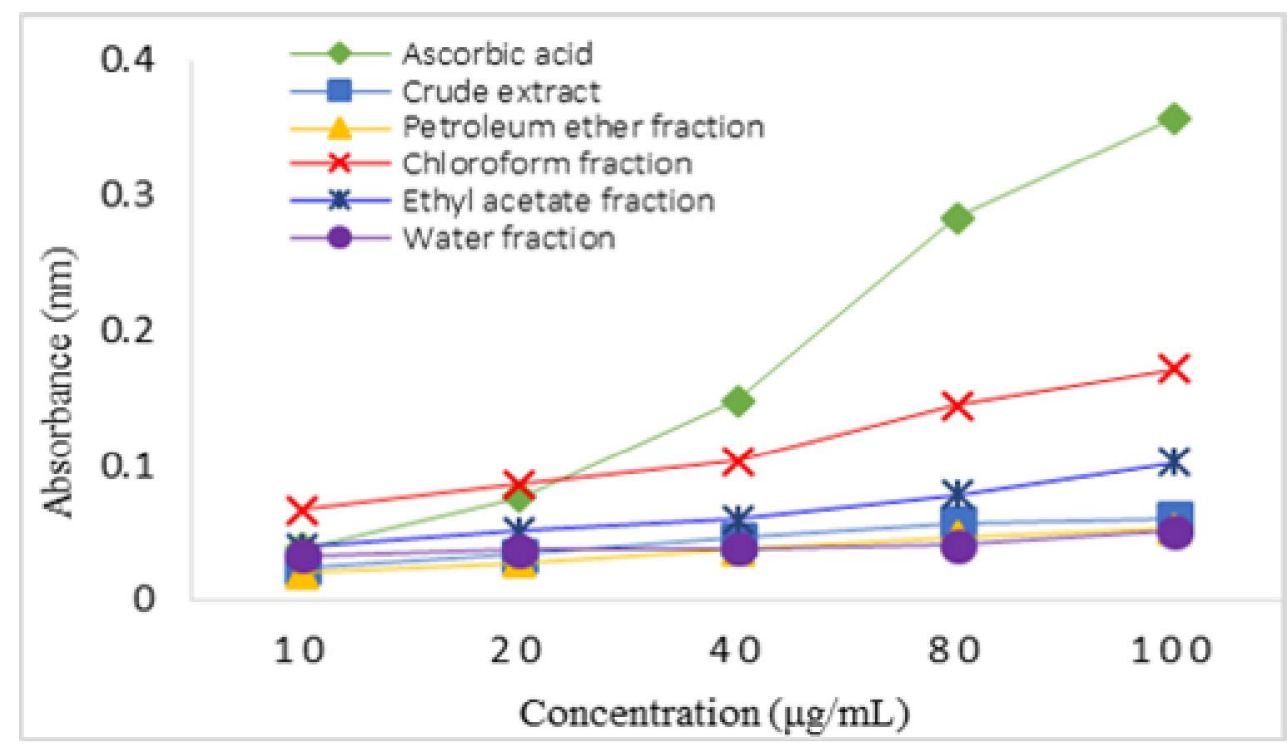

Figure 3. Total antioxidant capacities of crude extract of seeds of M. elengi and its four different fractions.

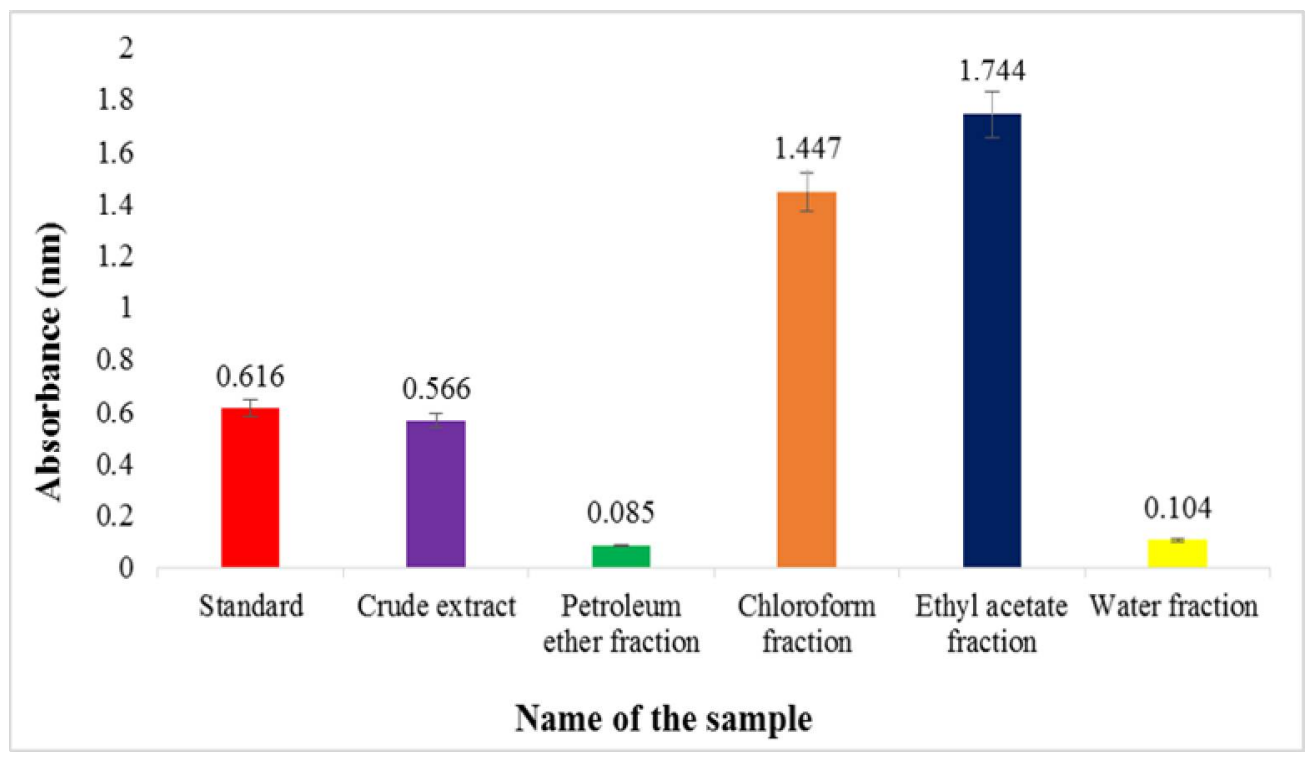

Figure 4. Ferric reducing power of crude extract of M. elengi seed and its different fractions.

In this method, the ethyl acetate fraction showed higher ferric reducing power (1.74 \pm 0.005$)$ compared with the standard ascorbic acid $(0.61 \pm$ 0.003). The water fraction showed lower activity. This result corroborates with other studies which showed that the ethyl acetate fraction had better ferric reducing power than the other fractions (Liu et al., 2011; Trabelsi et al., 2012). Thus, it can be seen that all the extracts of $M$. elengi seed possess ferric reducing power and the order of ferric reducing power was ethyl acetate $>$ chloroform $>$ methanol extract (crude) > water > petroleum ether. By these observations, it can be suggested that both solvent polarity and plant phenolic natures influence the antioxidant activity.

The DPPH free radical scavenging activity of crude extract, other test samples and standard ascorbic acid are shown in figure 5 . 


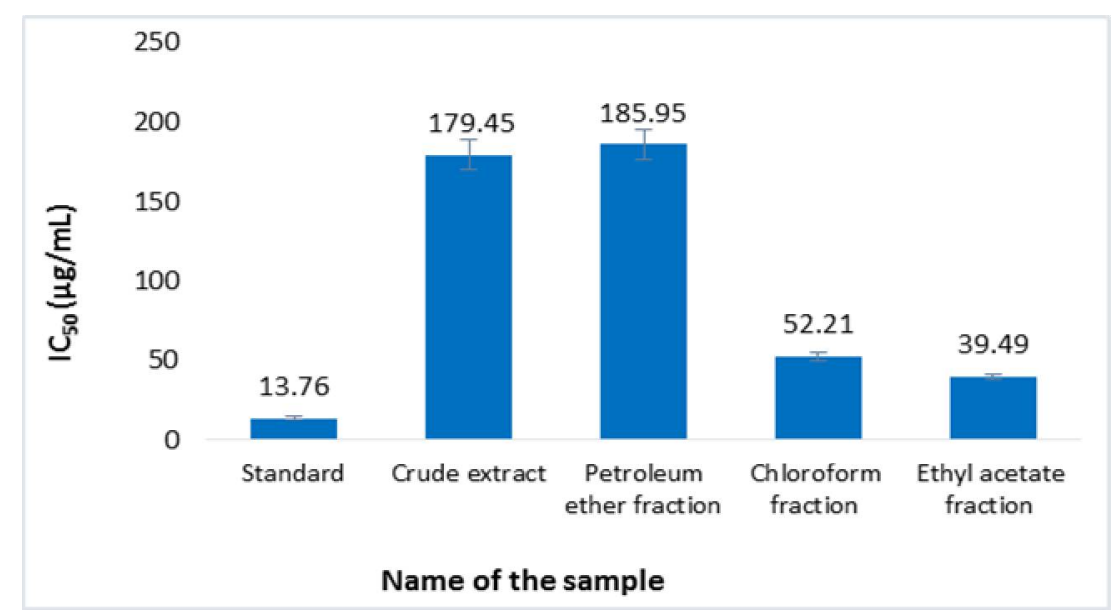

Figure 5. DPPH free radical scavenging activity of crude extract of $M$. elengi seed and its fractions.

Table 2. $\alpha$-Amylase inhibitory activity of crude extract of $M$. elengi seed, its fractionates and acarbose.

\begin{tabular}{lccccccc}
\hline $\begin{array}{l}\text { Name of } \\
\text { sample }\end{array}$ & $\begin{array}{c}\text { Conc. } \\
(\mu \mathrm{g} / \mathrm{ml})\end{array}$ & $\begin{array}{c}\% \text { Of inhibition } \\
\pm \mathrm{SD}\end{array}$ & $\begin{array}{c}\mathrm{IC}_{50} \\
(\mathrm{mg} / \mathrm{ml}) \\
\pm \mathrm{SD}\end{array}$ & $\begin{array}{c}\text { Name of } \\
\text { sample }\end{array}$ & $\begin{array}{c}\text { Conc. } \\
(\mu \mathrm{g} / \mathrm{ml})\end{array}$ & $\begin{array}{c}\% \text { of } \\
\text { inhibition } \\
\pm \mathrm{SD}\end{array}$ & $\begin{array}{c}\mathrm{IC}_{50}(\mathrm{mg} / \mathrm{ml}) \pm \\
\mathrm{SD}\end{array}$ \\
\hline $\begin{array}{l}\text { Acarbose } \\
\text { (standard) }\end{array}$ & 50 & $2.56 \pm 0.14$ & $0.62 \pm 0.003$ & $\begin{array}{c}\text { Chloroform } \\
\text { fraction }\end{array}$ & 50 & $0.56 \pm 0.06$ & $5.01 \pm 0.05$ \\
& 100 & $4.27 \pm 0.21$ & & & 200 & $3.06 \pm 0.22$ & \\
& 200 & $8.64 \pm 0.14$ & & & 500 & $5.13 \pm 0.11$ & \\
Crude & 500 & $48.82 \pm 0.54$ & & & 50 & $2.11 \pm 0.10$ & $7.31 \pm 0.05$ \\
extract & 50 & $1.52 \pm 0.30$ & $4.09 \pm 0.08$ & Ethyl & 5.05 & \\
& 100 & $2.13 \pm 0.11$ & & acetate & 100 & $3.42 \pm 0.20$ & \\
& 200 & $3.40 \pm 0.20$ & & fraction & 200 & $4.46 \pm 0.22$ & \\
Petroleum & 500 & $6.93 \pm 0.31$ & & & 500 & $5.49 \pm 0.11$ & \\
ether & 50 & $2.20 \pm 0.21$ & $5.08 \pm 0.07$ & Water & 50 & $2.2 \pm 0.01$ & $9.13 \pm 0.07$ \\
fraction & 100 & $2.56 \pm 0.14$ & & fraction & 100 & $3.34 \pm 0.10$ & \\
& 200 & $4.67 \pm 0.69$ & & & 200 & $4.08 \pm 0.03$ & \\
& 500 & $6.49 \pm 0.15$ & & & 500 & $4.94 \pm 0.12$ & \\
\hline
\end{tabular}

Free radical scavenging activity is mostly assigned to the phytochemicals present in the natural products derived food and is related with the total phenolic content or total flavonoid content of the food (Ehlenfeldt and Prior, 2001; Liu et al., 2008; Borneo et al., 2009). The ethyl acetate fraction of $M$. elengi seeds showed maximum DPPH free radical scavenging activity with the lowest $\mathrm{IC}_{50}$ value (39.49 $\pm 0.05 \mu \mathrm{g} / \mathrm{ml}$ ). The aqueous fraction did not show any scavenging activity. Many studies investigated the impact of the extracting solvents on antioxidant activity and found that antioxidant values obtained from organic solvent extraction were generally higher than those obtained with water (Cheplick et al., 2010; Sulaiman et al., 2011; Wang et al., 2012). This result is in agreement with other studies where the ethyl acetate fraction had better DPPH free radical scavenging activity than the other fractions (Desire et al., 2010; Liu et al., 2011). The ethyl acetate fraction probably due to its polarity allows the accumulation of a variety of antioxidant compounds such as polyphenols, flavonoids and other bioactive 
molecules that exhibit the strongest radicalscavenging activity. Thus, the order of DPPH free radical scavenging activity as ascorbic acid > ethyl acetate > chloroform > methanol extract (crude)> petroleum ether.

Overall the ethyl acetate fraction and crude methanolic extract of analyzed medicinal plant exhibited the highest total phenolic content, iron reducing power and DPPH radical scavenging activity whereas the chloroform fraction showed the highest total flavonoid content and total antioxidant activity.

The $\%$ inhibition of $\alpha$-amylase at 50, 100, 200, $500 \mu \mathrm{g}$ doses the crude extract and four fractionates of $M$. elengi and standard acarbose has been shown in table 2 .
Displayed highest percentage of inhibitory effects $(6.93 \pm 0.31 \%)$ on the $\alpha$-amylase enzyme at $500 \mu \mathrm{g} / \mathrm{ml}$ with an $\mathrm{IC}_{50}$ value of $4.09 \pm 0.08 \mathrm{mg} / \mathrm{ml}$. On the other hand, the water fraction showed lowest activity with highest $\mathrm{IC}_{50}$ value $9.13 \pm 0.07 \mathrm{mg} / \mathrm{ml}$. The standard exhibited the $\mathrm{IC}_{50}$ value of $0.62 \pm 0.003$ $\mathrm{mg} / \mathrm{ml}$ at the same concentration. The order of $\alpha$ amylase inhibitory activity was methanol > chloroform $>$ petroleum ether $>$ ethyl acetate $>$ water. The phytochemical assay of this study showed large amount of tannins, phenols and flavonoids present in methanol extract which may be the cause of the highest inhibitory activity (McDougall et al., 2005).

The result of brine shrimp lethality bioassay has been summarized in table 3.

Table 3. Effect of different extracts of M. elengi seed and vincristine sulfate on Artemia salina.

\begin{tabular}{lccccc}
\hline Name of sample & $\begin{array}{c}\mathrm{LD}_{50} \\
(\mu \mathrm{g} / \mathrm{ml})\end{array}$ & \multicolumn{2}{c}{$95 \%$ Confidence limits } & Regression equation & $\chi^{2}$ value \\
& & Lower & Upper & & \\
\hline Crude extract & 369.3 & 178.01 & 766.14 & $\mathrm{Y}=2.258+1.068 \mathrm{X}$ & 0.26009 \\
Petroleum ether & 6912.5 & 16.372 & 2918.56 & $\mathrm{Y}=3.419+0.4117 \mathrm{X}$ & 0.52541 \\
Chloroform & 915.7 & 156.73 & 5350.18 & $\mathrm{Y}=2.937+0.6966 \mathrm{X}$ & 0.48172 \\
Ethyl acetate & 127.1 & 73.958 & 218.41 & $\mathrm{Y}=2.687+1.099 \mathrm{X}$ & 0.51401 \\
Aqueous & 374.0 & 188.82 & 740.80 & $\mathrm{Y}=2.045+1.149 \mathrm{X}$ & 0.66255 \\
$\begin{array}{l}\text { Vincristine sulfate } \\
\text { (Standard) }\end{array}$ & 81.48 & 45.113 & 147.19 & $\mathrm{Y}=2.239+1.44 \mathrm{X}$ & 0.12610 \\
\hline
\end{tabular}

$\chi^{2}$ (chi-square) statistic is a single number that tells how much difference exists between the observed counts and the counts expected if there were no relationship at all in the population. A low value for chi-square means there is a high correlation between two sets of data.

The $\mathrm{LD}_{50}$ values of the crude extract, petroleum ether, chloroform, ethyl acetate and water fractions were found to be $369.3,6912.5,915.7,127.1$ and $374.0 \mu \mathrm{g} / \mathrm{ml}$, respectively. The standard vincristine sulfate had an $\mathrm{LD}_{50}$ value of $81.48 \mu \mathrm{g} / \mathrm{ml}$. The lowest $\mathrm{LD}_{50}$ value of $127.1 \mu \mathrm{g} / \mathrm{ml}$ was found in the case of ethyl acetate fraction, indicating its more potent cytotoxicity compared with other fractions in this study. The ethyl acetate fraction has been reported previously for its potent cytotoxic properties compared with other fractions (Mannan et al., 2017).

\section{Conclusions}

In present study, the antioxidant, $\alpha$-amylase inhibitory and cytotoxic activities of crude extract of seeds and its different fractions of a well-known medicinal plant, M. elengi were evaluated. The results of this study revealed that all extracts except the aqueous fraction of this medicinal plant contain polyphenols and flavonoids in good order. The chloroform and ethyl acetate fractions exhibited high antioxidant activity, iron reducing power and free radical scavenging activity; on the other hand least activity was exposed by petroleum ether and aqueous fractions. All samples except the aqueous fractions 
showed $\alpha$-amylase inhibitory activity. Compared to the standard, over all $\alpha$-amylase inhibitory activity of this plant was satisfactory. However, all test samples (other than the petroleum ether fraction) possess slight toxicity towards brine shrimp nauplii bioassay. Thus, the results recommend that the plant is a possible source of antioxidant and antidiabetic. However, further extensive studies are necessary to isolate and characterize the compounds responsible for the bioactivities.

\section{Acknowledgements}

The authors are thankful to the Chairmen, Department of Chemistry and Department of Biochemistry and Molecular Biology, University of Rajshahi, Rajshahi, Bangladesh.

\section{Conflict of interest}

No conflict of interest.

\section{References}

Ademiluyi, A.O. and Oboh, G. 2013. Soybean phenolicrich extracts inhibit key-enzymes linked to type 2 diabetes ( $\alpha$-amylase and $\alpha$-glucosidase) and hypertension (angiotensin I converting enzyme) in vitro. Exp. Toxicol. Pathol. 65, 305-309.

Borneo, R., Leon, A.E., Aguirre, A., Ribotta, P. and Cantero, J.J. 2009. Antioxidant capacity of medicinal plants from the Province of Córdoba (Argentina) and their invitro testing in a model food system. Food. Chem. 112, 664-670.

Cheplick, S., Kwon, Y.I., Bhownik, P. and Shetty, K. 2010. Phenolic-linked variation in strawberry cultivars for potential dietary management of hyperglycemia and related complications of hypertension. Bioresour. Technol. 101, 404-413.

Choi, H.Y., Jhun, E.J., Lim, B.O. 2000. Application of flow injection chemilumineacence to the study of radical scavenging activity in plants. Phyto. 14, 250-253

Dauer, A., Rimpler, H. and Hensel, A. 2003. Polymeric proanthocyanidins from the bark of Hamamelis virginiana. Planta. Med. 69, 89-91.

Desire, O., Rivière, C., Razafindrazaka, R., Goossens, L., Moreau, S., Guillon, J., Uverg Ratsimamanga, S., Andriamadio, P., Moore, N., Randriantsoa, A. and Raharisololalao, A. 2010. Antispasmodic and antioxidant activities of fractions and bioactive constituent davidigenin isolated from Mascarenhasia arborescens. J. Ethnopharmacol. 130, 320-328.
Ehlenfeldt, M.K. and Prior, R.L. 2001. Oxygen radical absorbance capacity (ORAC) and phenolic and anthocyanin concentrations in fruit and leaf tissues of Highbush blueberry. J. Agric. Food. Chem. 49, 22222227.

Gami, B. and Parabia, M.H. 2010. Pharmacognostic evaluation of bark and seeds of Mimusops elengi. Int. J. Pharm. Pharm. Sci. 29, 110-113.

Ganesh, G., Saurabh, M. and Sarada, N.C. 2013. Antioxidant and anti-inflammatory activities of the methanolic leaf extract of traditionally used medicinal plant Mimusops elengi L. Int. J. Pharm. Sci. Res. 5, 125-130.

Gupta, N. and Jain, U.K. 2011. Investigation of wound healing activity of methanolic extract of stem bark of Mimusops elengi Linn. Afr. J. Tradit. Complem. 8, 98103.

Harborne, J.B. 1998. Phytochemical methods: A guide of modern techniques of plant analysis. 3rd edition. Chapman and Hall Ltd, London. p. 279.

Jabir, K.V., Jayalakshmi, B. and Hashim, K.M. 2014. Invitro antidiabetic studies and phytochemical evaluation of Heracleum candolleanum. Asian. J. Plant. Sci. Res. 4, 31-36.

Karmakar, U.K., Sultana, R. and Biswas, N.N. 2011. Antioxidant, analgesic and cytotoxic activities of Mimusops elengi Linn. Leaves. Int. J. Pharm. Sci. Res. 2, 2791-2797.

Khandelwal, K.R. 2008. Practical Pharmacognosy Techniques and Experiments. 19th ed. Pune: Nirali Prakashan Publishers.

Koti, B.C. and Ashok, P. 2010. Diuretic activity of extracts of Mimusops elengi Linn Bark. Int. J. Green. Pharm. 4, 90-92.

Kwon, Y.I., Apostolidis, E. and Shetty, K. 2008. In vitro studies of eggplant (Solanum melongena) phenolics as inhibitors of key enzymes relevant for type 2 diabetes and hypertension. Bioresour. Technol. 99, 2981-2988.

Liu, H., Qiu, N., Ding, H. and Yao, R. 2008. Polyphenols contents and antioxidant capacity of 68 Chinese herbal suitable for medical or food uses. Food. Res. Int. 41, 363-370.

Liu, J., Wang, C., Wang, Z., Zhang, C., Lu, S. and Liu, J. 2011. The antioxidant and free-radical scavenging activities of extract and fractions from corn silk (Zea mays L.) and related flavone glycosides. Food. Chem. 126, 261-269.

Mannan, M.A., Alam, M.S., Mustari, F., Zahan, M.K., Ali, R., Haque, A.B.M.H., Zaman, S. and Talukder, D. 2017. In vitro Antioxidant, antimicrobial, insecticidal and cytotoxic activities of the medicinal plants: Allamanda cathartica and Mimusops elengi. European. J. Med. Plant. 20, 1-12.

Mariem, S., Hanen, F., Inès, J., Mejdi, S. and Riadh, K. 2014. Phenolic profile, biological activities and fraction analysis of the medicinal halophyte Retama raetam. S. Afr. J. Bot. 94, 114-121. 
Mariod, A.A., Ibrahim, R.M., Ismail, M. and Ismail, N. 2009. Antioxidant activities of phenolic rich fractions (PRFs) obtained from black mahlab (Monchema ciliatum) and with mahaleb (Prunus mahaleb) seedcakes. Food. Chem. 118, 120-127.

Mcdonald, S., Prenzler, P.D., Antolovich, M. and Robards, K. 2001. Phenolic content and antioxidant activity of olive extracts. Food. Chem. 73, 73-84.

McDougall, G.J., Shpiro, F., Dobson, P., Smith, P., Blake, A. and Stewart, D. 2005. Different polyphenolic components of soft fruits inhibit $\alpha$-amylase and $\alpha$ glucosidase. J. Agric. Food. Chem. 53, 2760-2766.

Meyer, B.N., Ferringm, N.R., Puam, J.E., Lacobsen, L.B., Nichols, D.E. and MeLaughlin, J.L. 1982. Brine Shrimp: a convenient general bioassay for active constituents. Planta. Med. 45, 31-34.

Oboh, G., Ademiluyi, A.O., Akinyemi, A.J., Henle, T.,Saliu, J.A. and Schwarzenbolz, U. 2012. Inhibitory effect of polyphenol-rich extracts of jute leaf (Corchorus olitorius) on key enzyme linked to type 2 diabetes $(\alpha$-amylaseand $\alpha$-glucosidase $)$ and hypertension (angiotensin Iconverting) invitro. $J$. Func. Food. 4, 450-458.

Olajire, A. and Azeez, L. 2011. Total antioxidant activity, phenolic, flavonoid and ascorbic acid contents of Nigerian vegetables. Afr. J. Food. Sci.2, 22-29.

Oyaizu, M. 1986. Studies on products of browning reaction: antioxidative activities of browning recation prepared from glucosamine. Jpn. J. Nutr. Diet. 44, 307-315.

Padhi, M. and Mahapatra, S. 2013. Evaluation of antibacterial potential of leaf extracts of Mimusops elengi. Int. Res. J. Biol. Sci. 2, 46-49.

Parvin, M.N., Sarwar, S., Chowdhury, S.A., Zakaria, H.M., Huda, N.H. 2009. In-vitro Cytotoxicity and Antioxidant Studies of Elaeocarpus serratus. S. J. Pharm. Sci, 2, 86-90.

Pranprawit, A., Heyes, J.A., Molan, A.L. and Kruger, M.C. 2015. Antioxidant activity and inhibitory potential of Blueberry extracts against key enzymes relevant for hyperglycemia. J. Food. Biochem. 39, 109-118.

Prasain, J.K., Carlson, S.H. and Wyss, J.M. 2010. Flavonoids and age-related disease: risk, benefits and critical windows. Maturitas. 66, 163-171.
Prieto, P., Pineda M. and Aguilar, M. 1999. Spectrophotometric quantitation of antioxidant capacity through the formation of a phosphomolybdenum complex: specific application to the determination of vitamin E. Anal. Biochem. 269, 337-341.

Shahwar, D. and Raza, M.A. 2009. In vitro antibacterial activity of extracts of Mimusops elengi against gram positive and gram negative bacteria. Afr. J. Microbiol. Res. 3, 458-462.

Slinkard, K., and Singleton, V.L. 1977. Total phenol analyses: automation and comparison with manual methods. Am. J. Enol. Vitic. 28, 49-55.

Sulaiman, S. F., Sajak, A.A.B., Ooi, K.L., Soupriatno and Seow, E.M. 2011. Effect of solvents in extracting polyphenols and antioxidants of selected raw vegetables. J. Food. Comp. Anal. 24, 506-515.

Trabelsi, N., Oueslati, S., Falleh, H., Waffo-Téguo, P., Papastamoulis, Y., Mérillon, J.M., Abdelly, C. and Ksouri, R. 2012. Isolation of powerful antioxidants from the medicinal halophyte Limoniastrum guyonianum. Food. Chem. 135, 1419-1424.

Uddin, A.H., Khalid, R.S. and Abbas, S.A. 2012. Determination of heavy metal concentration of different traditional medicine formulations available at the east coast region of Malaysia. Afr. J. Pharm. Pharmacol. 6, 1487-1491.

Wadood, A., Ghufran, M., Jamal, S.B., Naeem, M., Khan, A., Ghaffar, R. and Asnad. 2013. Phytochemical analysis of medicinal plants occurring in local area of Mardan. Biochem. Anal. Biochem. 2, 1-4.

Wang, Y., Huang, S., Shao, S., Qian, L. and Xu, P. 2012. Studies on bioactivities of tea (Camellia sinensis L.) fruit peel extracts: Antioxidant activity and inhibitory potential against $\alpha$-glucosidase and $\alpha$-amylase in vitro. Ind. Crops. Prod. 37, 520-526.

Wei, S.D., Zhou, H.C. and Lin, Y.M. 2010. Antioxidant activities of extract and fractions from the hypocotyls of the mangrove plant Kandelia candel. Int. J. Mol. Sci. 11, 4080-4093.

Zahid, H., Rizwani, G.H., Shareef, H., Mahmud, S. and Ali, T. 2012. Hypoglycemic and hypolipidemic effects of Mimusops elengi Linn. extracts on normoglycaemic and alloxan induced diabetic rats. Int. J. Pharmal. Bio. Archi. 3, 56-62. 